\title{
A Research on the System of Private Equity to Intellectual Property Rights
} BoSun ${ }^{1}, \mathrm{Xu} \mathrm{Yan}^{2}$, Wenbohao Zhu ${ }^{3}$

\author{
${ }^{1}$ Collaborative Innovation Center for 21st-Century Maritime Silk Road Studies, Research Institute of \\ International Services Outsourcing, Guangdong University of Foreign Studies, 2 North Baiyun Avenue, \\ Guangzhou, China \\ sbgz168@gdufs.edu.cn \\ ${ }^{2}$ School of Economics and Trade, \\ Guangdong University of Foreign Studies, \\ Guangzhou, Guangdong Province, China \\ yanxu0521@yahoo.com \\ ${ }^{3}$ School of Economics and Trade, \\ Guangdong University of Foreign Studies, \\ Guangzhou, Guangdong Province, China \\ 20150250001@gdufs.edu.cn
}

Key words: Securitization, private equity, intellectual property trust

Abstract: With the introduction to securitization and private equity, this paper studies the process and economic effects of securitization, and points out the possibility of private equity participating in securitization. Meanwhile, the paper explores the reasons why technology enterprises in most cases have trouble in raising capital through the analysis of the second data of technology and listed companies.

Combing with the special characteristics of the asset, intellectual property right is actually in the dilemma of whether raising capital can be made for technology enterprises, we will discuss the intellectual property trust and private equity. The possibility of financing, the enhanced ability to raise capital of intellectual property trust and ways to raise private equity will also be studied. Lastly we give the relevant suggestions on the problems which may occur in intellectual property trust.

\section{securitization}

\section{Basic Theories of the Securitization}

Securitization refers to the financial practice of pooling various types of contractual debt, such as residential mortgages, commercial mortgages, auto loans, or credit card debt obligations, and selling consolidated debt as pass-through securities, or collateralized mortgage obligation (CMOs) to various investors. The cash collected with the financial instruments underlying the security is paid to the various investors who have advanced money for that right. Financial securitization requires three basic elements, stable cash flow, asset "true sale" and the bankruptcy isolation of the risk to asset.

\section{The Process of Financial Securitization}

\section{The formation of asset pool.}

Issuers, based on considerations of certain circumstance to some extent, recognize the assets which lack liquidity but can produce a stable cash flow in the future. The specific standards could be the financing scale, time limitless, as well as some assessment specifications and auditing measures. The issuers put the homogeneous assets that have the same attributes into the asset pool, at the same time, establish financial goals and the expected targeting interests of the pool. 


\section{Set up the SPV transferred assets and recognize the asset "true sale".}

SPV is the independent main party who is of no risk to insolvency in law. They are the important carriers in the process of financial securitization. They can be the originators or other third parties with the target of achieving securitization of the underlying asset, hereby realizing the "risk isolation" in the legal level. The originator and SPV sign the sales contract to transfer the target assets to the SPV, making that this behavior is a "true sale".

\section{The restructuring and the internal rating to the underlying asset.}

After having obtained the underlying assets, the SPV needs to make asset management contracts with the originators or specified asset management services, meanwhile to settle the restructuring structure of the underlying assets and design plans to issuing securities, after that they find the appropriate payment agents and sign the agency pay agreements. At the same time, SPV needs to evaluate an internal rating of the issuing securities, there should be given the rating results by at least two and above rating agencies. According to the results of different rating agencies, the required credit enhancement will be given through the consultation in different levels.

\section{The credit enhancement.}

This enhancement can be divided into external and internal enhancement according to different sources. Internal enhancement mainly refers to the originators of securitized products. External enhancement refers to the third person or party to guarantee the insurance outside.

\section{Implement the securities rating and arrange securities issuance and sales.}

After the securitized credit enhancement, SPV needs to take the issuing securities rating once again for a deeper evaluation. Credit enhancement and ratings of securities can obtain higher credit rating, which will be helpful for the issue of securitized products. SPV needs to sign the underwriting agreements with the securities underwriters, through the process in which underwriters sell securities to investors. In the final stage, the SPV should determine stock rights and interests of the trustee.

\section{The payment of the underlying asset price.}

According to the secured income, SPV need to pay operating fees for people related to the issuers and a variety of services concerning with the securitized products in the process of the underlying assets, so as to achieve the purpose of financing for the issuers. Stock equity trustee manage the securitized assets and pay for them while getting maturity for securities rights and interests.

The whole process of the financial securitization is shown in Table 1 as the following: 


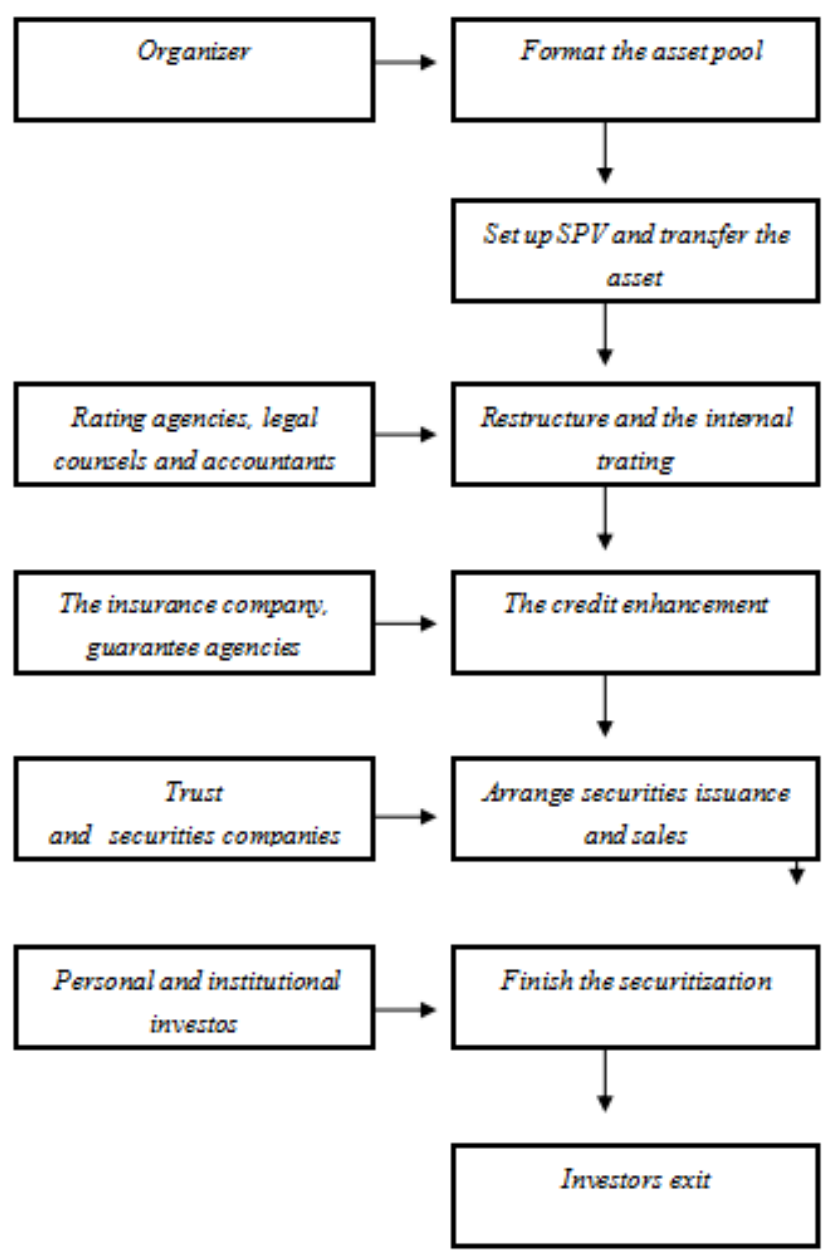

Table 1: The Process of Financial Securitization

Economic Effect of Securitization

Securitization in essence is actually a kind of structured debt financing based on the underlying assets, through structural arrangements and reorganization, aiming at making full use of the asset value of guarantees. Securitization, as a new way of financing, is a kind of indirect financing way giving priority to bank credit and capital markets. Economic effects of securitization mainly lie in the financing effect of promoters and originators and the mechanism of risk dispersing.

\section{PRVIATE EQUITY FINANCING}

\section{The Definition of Private Equity Financing}

Private equity financing, from the perspective of financiers, refers to a way of financing obtaining the funds required in the development required of investors through transferring the shareholders' equity in the process of financing. In our country, private equity funds still belong to new things. Compared with the European and American developed economic markets and their relevant situations, at present its development is relatively lagging behind to some extent. However for private equity, as a part of the multi-level capital market in our country, it is of great significance to accelerate the development of small and medium-sized enterprises, especially for the growth of technological small and mid-sized enterprises. 


\section{Effect beyond the Financing for Private Equity Funds}

Private equity fund investment is a kind of stock investment, this kind of attribute determines its effects beyond the financing. First, private equity investment can stimulate the effect of the consistent goals in the targeting action and measures. Second, private equity funds, its introduction of the essence is to follow the mechanism of risk and benefit sharing. Its revenue is closely related with the development of the enterprises, both of them have a common purpose which realizing the enterprise added value in the future. Objectively, this kind of interests binding forces private-equity funds stimulate the motivations and further drives to achieve the additional value-added services.

\section{The Role of Private Equity Fund in the Enterprise Life Cycle}

The role of private equity for the growth of small and medium-sized enterprises mainly embody in the following aspects: Firstly, to participate in the business start-up. Secondly, be beneficial to enterprise development, technical innovation and the creation of new products. Thirdly, be helpful for enterprises to expand financing channels and improve corporate governance.

\section{Exit Mechanism of Private Equity Funds}

Private equity funds aimed at exiting to obtain expected earnings. Its exit mechanism usually has the following forms: public listing, internal acquisitions or repurchase, external transfer shares and bankruptcy liquidation.

\section{Financing difficulties of Technological Enterprises}

Difficulty of financing problems for small and medium-sized enterprises, especially for technological enterprises, not only exists in the present stage of China, but also in other developing countries such as India, Brazil, etc. It is as well as widespread in developed countries like Europe, the United States and Germany. Difficulty of financing problems is mainly manifested in such aspects as the narrow financing channels; high financing costs and limited financing scale; unreasonable financing structure, funding period mismatch and seriously lack of long-term equity capital.

\section{INTELLECTUAL PROPERTY RIGHTS TRUST ON PRIVATE EQUITY}

\section{The Necessity to Intellectual Property Securitization}

The necessity of securitization of intellectual property rights embodied in these aspects: one is to relieve financing difficulties of single channel problems for enterprises, especially small and mid-sized enterprise; the second one is that financial securitization helps to achieve the industrialization of intellectual property rights, thus forming a whole system. The third one is the securitization of intellectual property benefits the accumulation of intellectual property rights which are appropriate to securitization.

\section{The Difficulties in the Process of Operation and Relevant Suggestions}

Intellectual property rights trust can speed up the intellectual property rights transactions revitalize technological enterprises and stimulate the liquidity of the intellectual property assets. As a new attempt, the issure to the issue to intellectual property trust is that, through restructuring which helps to increase liquidity for intellectual property rights, the intellectual property rights are discounted with future cash flow to achieve the financing process for the development of technological enterprises themselves. But in the process of private equity operation to intellectual property rights trust, under the background of the market mechanism, the intermediary service is restricted; laws and regulations construction is relatively limited. All of these problems are substantial impediments that slower the advancement of securitization to intellectual rights. Therefore a portfolio of effective measures should be taken as soon 
as possible at the present stage.

First and foremost, the intellectual property rights trust system and the concerning laws and regulations construction is not yet complete. In our country, the intellectual property rights trust, as a kind of new things, its relevant laws and regulations as well as the market system have not yet been established, thus producing many problems in practice and operation. It is difficult to get solutions for the typical problems timely and effectively. For this, the need to take relevant legislative and regulatory measures for intellectual property trust comes first and there should be setting up intellectual property trust market self-discipline organizations to promote the healthy development of the intellectual property rights trust.

Second of all, there is extremely lack of specialized agencies to professionally take the special work. In the process of securitization of Intellectual property rights, how to evaluate the value of intellectual property is in the dire need to solve. The lack of relevant professional organizations and professionals lead to a larger deviation to the evaluation of intellectual property rights. In order to ensure the smooth operation of the financial securitization of intellectual property rights, it is of great a need to improve the construction of intellectual property intermediary services institutions as soon as possible, in order to speed up the cultivation of related personnel and improve their professional levels. Specifications of intellectual property assessment do not always get perfect at one time. It needs a corresponding encouraging policies conducted by the governments and related departments step by step. Meanwhile, on the premise of legal regulations and policies, there can be reasonable introduction of intermediary service institutions and relevant technology for further development.

Last but not the least, the private equity operation should avoid touching the red lines of the laws and regulations of the intellectual property rights trust. This is not only in view of the intellectual property trust, but suggestions to private equity funds. Intellectual property rights, as a kind of intangible assets involving complex ownership, it need a detailed understanding of whether the intellectual property right are completely owned by the shareholder. After the transfer of intellectual property rights, whether the assignee has the right of defense to the third party is a key problem. Since the ownership will likely trigger legal problems, to pay attention to financing which can help it far away from the legal red line, therefore refraining from illegal financing to private equity funds is above all in order to avoid unnecessary legal disputes.

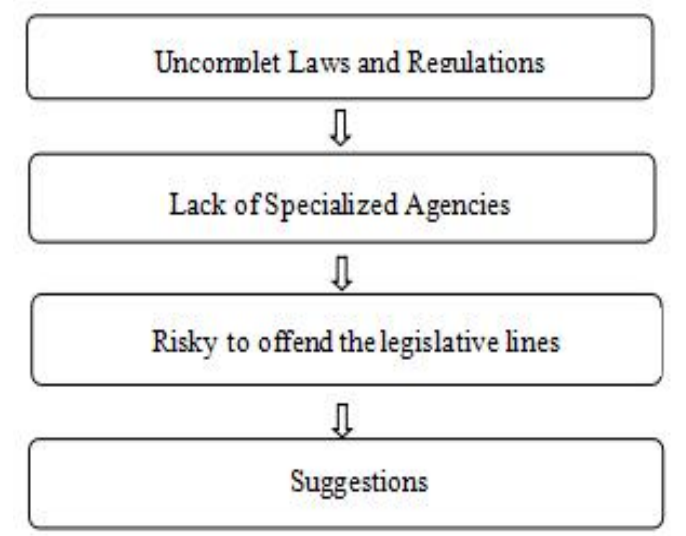

Table 2: The difficulties in the process of operation 


\section{CONCLUSIONS}

Through the analysis of financial securitization, this paper draws the conclusion that the intellectual property rights which can be conducted financial securitization have three basic elements: stable cash flow, asset "true sale" and the bankruptcy isolation of the risk of asset. At the same time, financial securitization, as a new type of income-producing assets financing way, can revitalize the liquidated assets, make an extension of financing channels to science and technology enterprises and spread the management and financial risk of technological enterprises, thus improving their financing structure in the future.

Private equity funds, as a kind of stock investment, have effect beyond the financing. Firstly, it can produce action effect with consistent target; Secondly, it can take the initiative to provide additional value-added services for the enterprises. Private equity fund plays an important role in the whole life cycle for the enterprises. Thirdly, private equity funds make full use of a series of withdrawal or exist mechanisms to get expected return.

Technological enterprises, because of the structure of multi-level capital market and the substantial flaws, have the financing puzzlements as follows: the narrow financing channels; high financing costs and limited financing scale; funding period mismatch problems; seriously lack of long-term equity capital resulting from the unreasonable financing structure. Intellectual property rights trust of private equity technological enterprises financing opens a new financing way, through the construction of the asset pool, realizing the most valuable assets in the technological enterprises, and making it as the underlying assets with the trust of the intellectual property rights. The trust companies, as the principal, transfer the beneficial right of the underlying assets to private equity funds by bearing the related risks and benefits for private equity funds, so as to realize the purpose of improving the capital structure for the technological enterprises through intellectual property financing.

But in the process of the intellectual property trust operation for the private equity, there are still are existiong the following problems: the defective system and imperfect related laws and regulations, the lack of professional intermediary service agencies and the risky to tough the legal line for the inexperienced companies. All of those are the problems the regulators need to pay close attention to. The solution of these problems is of great significance to better prompt the healthy development of private equity's intellectual property rights trust.

\section{Acknowledgment}

This work was supported in part by a grant from Guangdong province science and technology planning project. (2013B040404009)

\section{REFERENCE}

[1] Nabil Amaraa, Rejean Landrya, Namatie Traoreb. Managing the protection of innovations in knowledge —intensive business services, Research Policy, 2008, (37) : 1530—1547.

[2] Lerner, Josh; Leamon, Ann; Hardymon, Felda. Venture Capital, Private Equity, and the Financing of Entrepreneurship. 2012:1. ISBN: 9780470591437

[3] Private equity investment- Real Estate Financing Case Studies_5257. 2013:08 http://www.docin.com/p-88863942.html

[4] A Study of Legal Issues in Intellectual Property Rights Securitization in Mainland China. Jia Lun Lai, Jiann Jong Guo:2011. Networked Digital Library of Theses and Dissertations 
[5] Intellectual Property Securitization and Growth Capital in Retail Franchising. Tahir M. Nisar. Journal of Retailing [0022-4359] Nisar, Tahir yr:2011 vol:87 iss:3 pg:393 -405

[6] Intellectual property securitization. Solomon, Dov; Bitton, Miriam. Cardozo Arts \& Entertainment Law Journal, Spring, 2015, Vol.33(1), p.125-179

[7] Intellectual Property Operations and Implementation in the 21st Century Corporation. Bryer, Lanning Lebson, Scott J; Asbell, Matthew D: 2011

[8] SECURITIZATION: A new approach to the framing of the "war on terror" . Vultee, Fred. Journalism Practice, 2010, Vol.4(1), p.33-47

[9] The law of transnational securitization.David Ramos. Muñoz Kevin Ingram 2010

[10] Securitization of Intellectual Property -Technology Trust or Patent Securitization. Byoung Youn Kim. KSI (Hanguk Haksul Chungbo), 2007, Vol.26(1), p.253 ISSN: 1226-3362 